Gut, 1986, 27, 1173-1180

\title{
Studies of the free faecal amines of infants with gastroenteritis and of healthy infants
}

\author{
K E MURRAY, R F ADAMS, J W EARL AND K J SHAW \\ From the Division of Food Research, CSIRO, North Ryde, NSW, Australia and the Royal Alexandra \\ Hospital for Children, Camperdown, NSW, Australia
}

SUMmaRY The free primary amines present in the faeces of 44 infants (1-18 months) with gastroenteritis have been examined by field desorption mass spectrometry of the lactone form of their fluorescamine derivatives without their prior separation. $p$-Tyramine, 2-phenylethylamine, the diamines, putrescine and cadaverine and several of their acyl derivatives were common constituents, but a number of other amines were also characterised. Using thin layer chromatography and field desorption mass spectrometry of the amine dansyl derivatives a comparative study was made of the faecal amines of 13 selected infants with gastroenteritis (diarrhoea) and of 13 healthy infants. $p$-Tyramine, the most abundant amine, was significantly higher $(\mathrm{p}=0.02)$ in the sick infants. The overall presence of $p$-tyramine was more significantly related to the diet of the infants. Faecal tyramine was low in breast fed infants but significantly higher $(p=0 \cdot 01)$ in infants fed cow's milk.

In the CSIRO Division of Food Research, studies are proceeding on the effect of certain food constituents on the gut microflora including their role in amine production. Apart from conclusions inferred from urinary amine analysis, little is published concerning the production in vivo of amines by the human gut microflora. As exploratory studies to develop methodology and to obtain basic data, we elected to examine the production of amines in the gut as reflected by their presence in the faeces of sick and healthy infants. The choice of subjects was made because of the ready availability of specimens from the hospital environment. In this paper we describe, firstly, the result of screening by field desorption mass spectrometry of amines as their fluorescamine derivatives in the faeces of 44 infants hospitalised with gastroenteritis and secondly, a comparative study by thin layer chromatography and field desorption mass spectrometry of the faecal amines as their dansyl derivatives in 13 diarrhoetic and 13 healthy infants.

\section{Methods}

AMINE SCREENING STUDY

Faecal specimens. were obtained from infants ad-

Address for correspondence: Dr K E Murray. Division of Food Research. CSIRO, P.O. Box 52, North Ryde, NSW, Australia.

Received for publication 6 February 1986 mitted to the Edgar Stephens Gastroenteric Ward of the Royal Alexandra Hospital for Children in Sydney. The specimens were taken without selection soon after admittance. They were kept at $-30^{\circ} \mathrm{C}$ until processed.

CASES OF INFANT DIARRHOEA

Specimens were again obtained from the Edgar Stephens Ward and handled as above but were from 13 infants (mean age 7 months, range $1-23$ months including nine in the range 3.8 months) all of whom were diarrhoetic (Table 1, A-M).

HEALTHY INFANTS

Specimens were collected from 13 healthy infants (mean age 8 months, range 4-12 months) (Table 1 , $\mathrm{N}-\mathrm{Z}$ ). They comprised: five patients from the above hospital (N-R), admitted for reasons unrelated to gastric problems and who were receiving no drug therapy; five infants attending a baby health centre at North Ryde (S-W); and three infants, relatives of CSIRO laboratory staff $(\mathrm{X}-\mathrm{Z})$.

EXTRACTION AND DERIVATISATION OF AMINES

Method I

Amines were separated by ion exchange, largely following a procedure for urinary amines, ${ }^{1}$ from the faeces of the 44 infants and derivatised to form the fluorescamine derivatives ${ }^{2}$ (lactone form) as fol- 
Table 1 Characteristics and diet of diarrhoetic $(A-M)$ and healthy infants $(N-Z)$

\begin{tabular}{|c|c|c|c|c|c|c|c|}
\hline Infant & Sex & $\begin{array}{l}\text { Age } \\
\text { (mths) }\end{array}$ & $\begin{array}{l}\text { Main item } \\
\text { of diet }\end{array}$ & Infant & Sex & $\begin{array}{l}\text { Age } \\
\text { (mths) }\end{array}$ & $\begin{array}{l}\text { Main item } \\
\text { of diet }\end{array}$ \\
\hline A & $\mathbf{M}$ & 7 & $\mathrm{CMF}^{*}$ & $N$ & $\mathbf{F}$ & 4 & nd \\
\hline B & $\mathrm{F}$ & 3 & nd & $\mathrm{O}$ & $\mathbf{M}$ & 7 & $\mathrm{CMF}$ \\
\hline $\mathrm{C}$ & $\mathbf{M}$ & 1 & $\mathrm{CMF}$ & $\mathrm{P}$ & $\mathbf{M}$ & 4 & $\mathrm{CMF}$ \\
\hline D & $F$ & 23 & $\mathrm{CMF}$ & Q & $F$ & 12 & nd \\
\hline $\mathrm{E}$ & $\mathbf{M}$ & 7 & nd & $\mathbf{R}$ & $\mathbf{M}$ & 10 & nd \\
\hline $\mathrm{F}$ & $\mathrm{F}$ & 3 & nd & $\mathrm{S}$ & $\mathbf{M}$ & 12 & $\mathrm{CM}$ \\
\hline G & $\mathbf{M}$ & 3 & $\mathrm{CM}$ & $\mathrm{T}$ & $\mathrm{F}$ & 9 & BF \\
\hline $\mathrm{H}$ & $\mathbf{F}$ & 3 & nd & $\mathrm{U}$ & $\mathrm{F}$ & 8 & $\mathrm{BF}$ \\
\hline I & $\mathbf{M}$ & 8 & SF & V & $\mathrm{F}$ & 6 & $\mathrm{BF}$ \\
\hline $\mathbf{J}$ & $\mathbf{M}$ & 4 & $\mathrm{CM}$ & W & $\mathbf{M}$ & 12 & $\mathrm{CM}$ \\
\hline K & $\mathrm{F}$ & 5 & $\mathrm{CMF}$ & $X$ & $\mathrm{~F}$ & 4 & $\mathrm{CMH}$ \\
\hline $\mathbf{L}$ & $\mathbf{M}$ & - & nd & $\mathrm{Y}$ & $\mathrm{F}$ & 4 & nd \\
\hline $\mathbf{M}$ & $\mathbf{M}$ & 14 & nd & $\mathrm{Z}$ & $\mathrm{F}$ & 11 & $\mathrm{BF}$ \\
\hline
\end{tabular}

${ }^{*} \mathrm{BF}=$ breast fed; $\mathrm{CM}=$ cow's milk; $\mathrm{CMF}=$ cow's milk formulation; $\mathrm{CMH}=$ cow's milk formulation 'humanised'; $\mathrm{SF}=$ soya formulation; nd = no data.

lows. Faeces $(1.0 \mathrm{~g})$, distilled water $(6 \mathrm{ml})$ and several glass beads were mechanically shaken for 10 min in a $20 \mathrm{ml}$ screw topped culture tube. The wall of the tube was washed down with distilled water $(3 \mathrm{ml})$ and the tube was centrifuged for $10 \mathrm{~min}$ at $1300 \mathrm{~g}$. The supernatant $(8 \mathrm{ml})$, adjusted to $\mathrm{pH} 7 \cdot 0$ if necessary, was transferred to a column $(10 \mathrm{~cm} \times 1 \mathrm{~cm})$ of an ion exchange resin (Bio-Rex 70, 100-200 mesh, $\mathrm{H}^{+}$form, Bio-Rad Laboratories, Richmond, CA). The column was washed with water $(20 \mathrm{ml})$, the amines eluted with $1.5 \mathrm{~N} \mathrm{HCl}(30 \mathrm{ml})$ and the eluate evaporated to dryness in $100 \mathrm{ml}$ pear shaped flasks on a rotary evaporator. The residue was taken up in $0.2 \mathrm{M}$ borate buffer $(2 \mathrm{ml})$ and adjusted to $\mathrm{pH}$ $8 \cdot 8$ using sodium hydroxide. While the solution was vigorously stirred on a vortex mixer, $100 \mu$ l of a solution of fluorescamine (Fluram, Hoffman La Roche, Switzerland, $10 \mathrm{mg} / \mathrm{ml}$ in acetone) was added. The solution was adjusted to $\mathrm{pH} 4.0$ with $1 \mathrm{~N}$ $\mathrm{HCl}$ and the fluorescamine derivatives were extracted as their lactone form into $3 \mathrm{ml}$ chloroform.

\section{Method II}

To permit quantification (not possible with Method I) of the faecal amines of diarrhoetic and healthy infants a solvent extraction technique using ethyl acetate was developed followed by dansylation. This proved to be simpler than the cation exchange procedure above and has the advantage that ammonia and aliphatic diamines are poorly extracted. Their abundance complicates separations by thin layer chromatography. Ethyl acetate also extracts phenol and $p$-cresol in sufficient yield $(20-40 \%)$ to demonstrate their presence. The procedure was as follows: faeces $(0.25 \mathrm{~g}), 1.5 \mathrm{ml} \mathrm{KCl}-\mathrm{HCl}$ buffer $(0 \cdot 1 \mathrm{M}, \mathrm{pH} 2 \cdot 2)$, petroleum ether $\left(60-80^{\circ} \mathrm{C}, 1.5 \mathrm{ml}\right.$, to remove fats) and several glass beads were mechanically shaken in a $10 \mathrm{ml}$ screw top culture tube until the faecal solids were dispersed. The tube was then centrifuged at about $1300 \mathrm{~g}$ for $10 \mathrm{~min}$ to separate the solid material and the clear aqueous phase $(1.0 \mathrm{ml})$ was transferred to a fresh culture tube. Borate buffer $(0 \cdot 2 \mathrm{M}$ sodium tetraborate, adjusted to $\mathrm{pH} 10.4$ with sodium carbonate $0.50 \mathrm{ml}$ ), was added along with sufficient $1.0 \mathrm{~N}$ sodium hydroxide (about $0.17 \mathrm{ml}$ ) to return the $\mathrm{pH}$ to $10 \cdot 4$. Water saturated ethyl acetate, $6 \mathrm{ml}$, was added, the tube shaken for $30 \mathrm{~s}$ and centrifuged at low speed to separate the layers completely. The solvent layer was cleanly drawn off by a $10 \mathrm{ml}$ glass syringe fitted with a stainless steel capillary $(10 \mathrm{~cm} \times 1 \mathrm{~mm}$ ID) with the tip positioned about $1 \mathrm{~mm}$ above the interface. To improve efficiency of extraction the tube and syringe were attached with clips to a vertical wooden support. The extraction was repeated and the combined extract plus $50 \mu \mathrm{l}$ of $1.0 \mathrm{~N}$ $\mathrm{HCl}$ in a tube $140 \mathrm{~mm} \times 20 \mathrm{~mm}$ was taken to near dryness at $40^{\circ} \mathrm{C}$ by a stream of nitrogen.

\section{Dansylation}

The wet residue above was taken up in $1 \mathrm{ml}$ of $10 \%$ w/v sodium carbonate $(1 \mathrm{ml})$. Dansyl chloride (5-dimethylamino-naphthalene-1-sulphonyl chloride, Pierce Chemical Co., Rockford, Il, USA) solution ( $3 \mathrm{ml}, 1 \mathrm{mg} / \mathrm{ml}$ in acetone) was added, the tube shaken and stood overnight away from light. Most of the acetone was removed at $40^{\circ} \mathrm{C}$ by a stream of nitrogen and the remaining aqueous solution was shaken with ethyl acetate $(2 \mathrm{ml})$. The liquid layers were allowed to separate completely

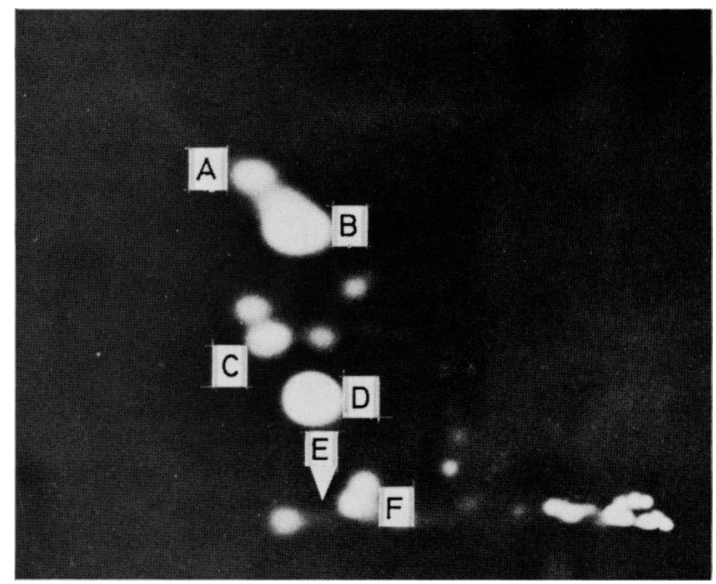

Fig. 1 Two dimensional thin layer chromatogram of dansylated faecal amines and phenol. Infant G, Table 1. A, phenol; $B$, reagent; $C$, phenylethylamine; $D$, tyramine; $E$, tryptamine; $\mathrm{F}, \mathrm{NH}_{3}$-diamines. 
and granular anhydrous sodium sulphate was added until the aqueous layer was just immobile. This allowed the ethyl acetate to be decanted off into a $10 \mathrm{~cm} \times 12 \mathrm{~mm}$ screw topped tapered tube. The solid sodium sulphate layer was washed without disturbance with ethyl acetate $(2 \mathrm{ml})$ which was added to the extract. The solvent was removed at $40{ }^{\circ} \mathrm{C}$ by a stream of nitrogen and the dry dansylated material was taken up in $1 \mathrm{ml}$ toluene. Some insoluble nondansylated material was separated by centrifuging and the clear toluene solution transferred to a $2 \mathrm{ml}$ screw topped phial for storage at $-20^{\circ} \mathrm{C}$ away from light.
THIN LAYER CHROMATOGRAPHY

Thin layer chromatography was applied to the dansylated amines from the 13 diarrhoetic and the 13 healthy infants in two ways. Firstly, two dimensional development of each specimen was used to obtain good resolution (Fig. 1). The methodology was basically that of Seiler. ${ }^{3}$ In one solvent toluene was substituted for benzene. The solvents were: first direction, ethyl acetate:cyclohexane (3:2); second direction, toluene:triethylamine (10:1). Secondly, one dimensional development of multiple extracts was employed to obtain an overview of the two infant groups on single plates and for quantitative

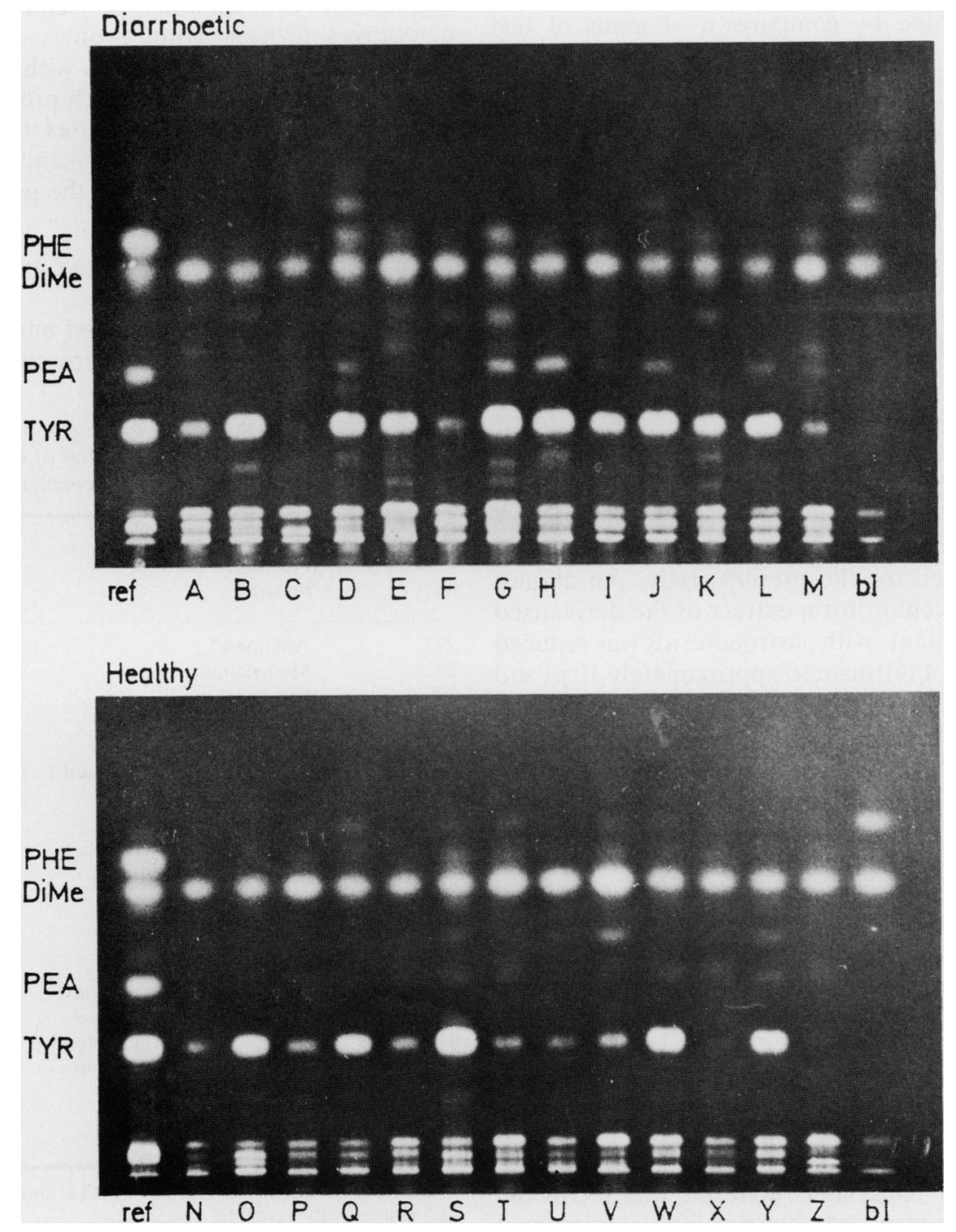

Fig. 2 One dimensional thin layer chromatograms of dansylated faecal amines and phenol of diarrhoetic and healthy

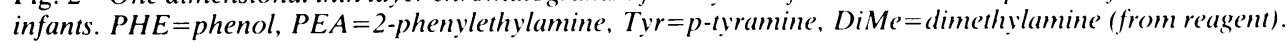


scanning (Fig. 2). The solvent was toluene:triethylamine (10:1). The plates were $20 \times 20 \mathrm{~cm}$ Silica Gel 60 (Merck, Darmstadt, FRG) for two directional development and similarly for single development but with a concentration zone. The developed plates were observed under UV (max. $375 \mathrm{~nm}$ ) after standing in the vapour of triethylamine for $15 \mathrm{~min}$ to optimise fluorescence. They were photographed under similar conditions with Polaroid film 107 with a Kodak CC20Y filter. The singly developed plates (Fig. 2) were scanned by a Shimadzu Dual Wave Length TLC Scanner, Model CS-910, (Shimadzu, Kyoto, Japan) to provide quantitative estimates of $p$-tyramine and phenylethylamine by comparison of areas of test samples with areas of extracted standards.

\section{Recovery and reproducibility}

To evaluate recovery of tyramine and phenylethylamine from faeces known amounts of the amines were added to aliquots of a faecal sample which was found to have no detectable amounts of the amines. The 'spiked' samples were processed by Method II and recoveries calculated by comparison with amine standards that were not extracted. Reproducibility of the method was assessed from similar extracted samples.

\section{MASS SPECTROMETRY}

The application of field desorption mass spectrometry to the examination of primary amines as the lactone form of their fluorescamine derivatives has been described. ${ }^{4}$ The instrument and conditions were unchanged for the present study. An aliquot $(100 \mu \mathrm{l})$ of the chloroform extract of the derivatised amines from infants with gastroenteritis was reduced with a stream of nitrogen to approximately $10 \mu \mathrm{l}$ and applied by microsyringe to the field emitter. At the optimum conditions for their emission the emitter heating current was $18-20 \mathrm{~mA}$ for the monoamine derivatives (MW amine +260 ) and 20-22 $\mathrm{mA}$ for the diamine derivatives (MW diamine +520 ). While gradually increasing the current from $18 \mathrm{~mA}$ spectra were recorded linearly at 5 mass units per second over the mass range $\mathrm{m} / \mathrm{z} 270-440$ for the monoamine derivatives and similarly from $20 \mathrm{~mA}$ spectra were recorded over the range $\mathrm{m} / \mathrm{z} 580-750$ for the diamine derivatives. Field desorption mass spectrometry was also used in conjunction with thin layer chromatography to identify the more abundant amines as the molecular ions of their dansyl derivatives (MW monoamine +233 , MW diamine +466 ) after their separation by two dimensional thin layer chromatography. The dansylated material was recovered from the flourescent area by scraping the adsorbent from the thin layer chromatography plate, transferring it to a small sintered glass funnel and washing it with a total of $0.5 \mathrm{ml}$ of toluene. The solvent was removed in a conical phial by a stream of nitrogen and the dansylated material was taken up by $10 \mathrm{ul}$ of toluene for application to the emitter.

\section{Results}

FIELD DESORPTION MASS SPECTROMETRY SPECTRA OF FLUORESCAMINE (LACTONE) DERIVATIVES OF AMINES

With a few exceptions the field desorption spectra of the primary amine derivatives show only their molecular ions. ${ }^{4}$ For this reason the field desorption spectra obtained by scanning over the molecular ion regions of the monoamine- and the diaminederivatives provide good profiles of the primary amines present in the mixtures without recourse to their prior separation. Two such profiles are shown in Figure 3. Table 2 summarises the information concerning the identity and frequency of occurrence of primary amines indicated in the profiles from the 44 infants with gastroenteritis.

\section{THIN LAYER CHROMATOGRAPHY OF}

\section{DANSYL AMINES}

The 26 specimens of dansylated amines from diarrhoetic and healthy infants were chromatographed

Table 2 Amines indicated to be present and their frequency in the molecular ion profiles of the faecal amine-flurams of children with gastroenteritis

\begin{tabular}{lll}
\hline $\begin{array}{l}\text { Amine fluram } \\
\text { Molecular ion } \\
m / z\end{array}$ & $\begin{array}{l}\text { Primary amine indicated } \\
\text { present }\end{array}$ & $\begin{array}{l}\text { Amine present in } \\
\text { per cent of } \\
\text { samples }\end{array}$ \\
\hline 277 & & \\
291 & Ammonia* & 48 \\
305 & Methylamine & 57 \\
321 & Ethylamine & 59 \\
333 & Ethanolamine* & 43 \\
347 & Butylamine (iso?) & 18 \\
359 & Methylbutylamine (2- and 3-) & 16 \\
361 & Cyclohexylamine* & 9 \\
+ & 5-aminopentanol & 11 \\
381 & Histamine & 66 \\
397 & 2-Phenylethylamine* & 73 \\
413 & p-Tyramine* & 70 \\
420 & Octopamine/dopamine & 9 \\
390 & Tryptamine* & 9 \\
404 & Acetylputrescine & 55 \\
418 & Acetylcadaverine/propionyl & \\
& Propionylcadaverine/butyryl & \\
432 & Butyrylcadaverine & 70 \\
608 & Putrescine* & 25 \\
620 & Cadaverine* & 68 \\
& & 91 \\
\hline
\end{tabular}

*Identity subsequently confirmed by TLC and FD-MS of dansyl derivatives with authentic specimens.

+ When present in small amount histamine fluram does not give a molecular ion but a group of iona-m/z372 $(\mathrm{M}+\mathrm{H})^{+}$; $\mathrm{m} / \mathrm{z} 369(\mathrm{M}-2 \mathrm{H})^{+}$and $\mathrm{m} / \mathrm{z} 353\left(\mathrm{M}-\mathrm{H}_{2} \mathrm{O}\right)^{+}$. 


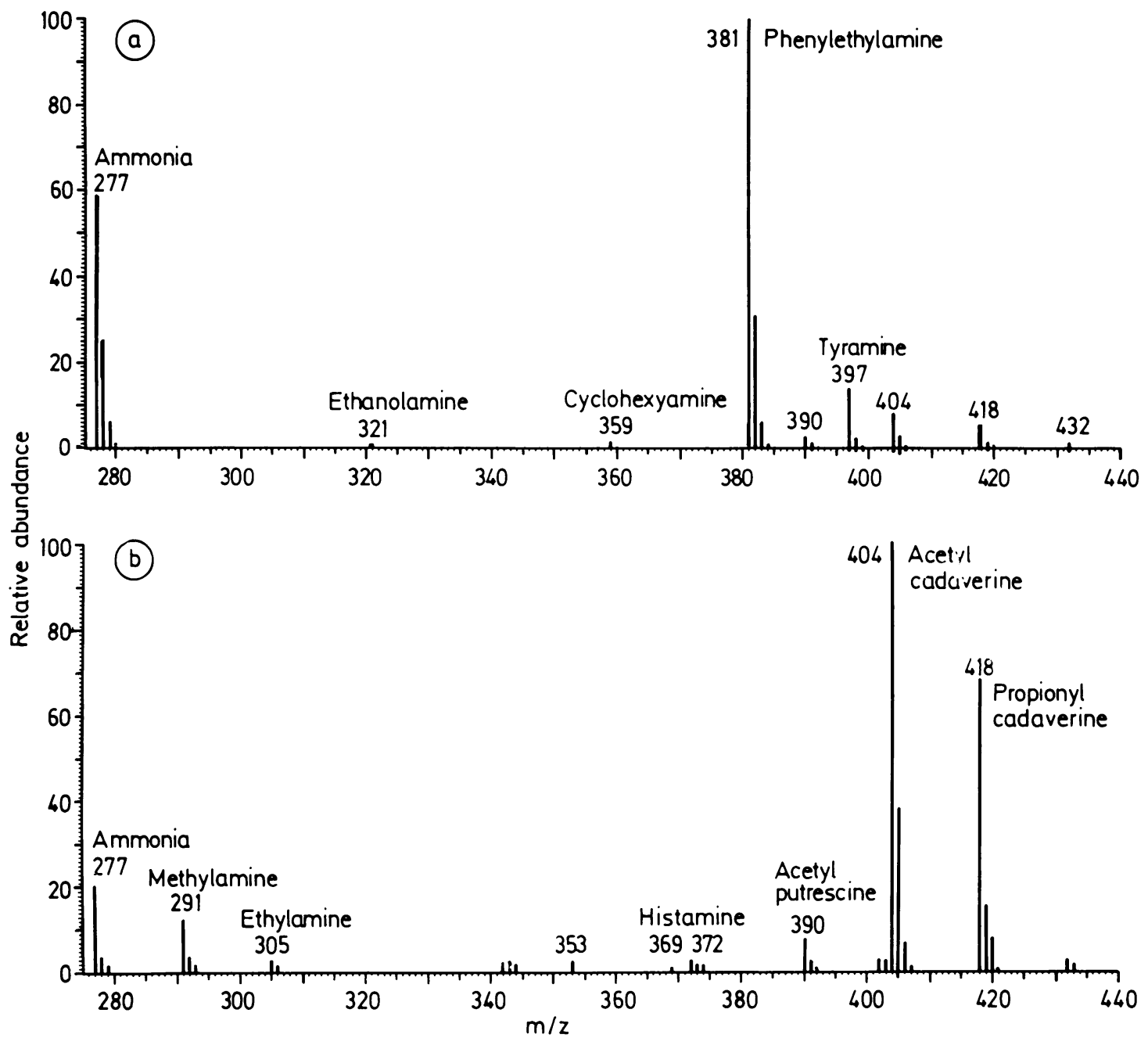

Fig. 3 Mass spectral profiles of faecal primary amines of children with gastroenteritis. (a), male, 18 months. (b), female, 4 months.

in two dimensions. The identity of the major spots was established by the thin layer chromatography of dansylated pure amines and by their molecular ions obtained by field desorption mass spectrometry of material recovered from the thin layer chromatography plates. Phenol was also identified as its dansyl derivative and was extracted along with the amines. It occurred in several specimens (Fig. 1 and $2)$. Our interest became centred on the presence of $p$-tyramine, 2-phenylethylamine and tryptamine on account of their physiological activity. Other amines will be further considered in another publication. It was clear from the 2-dimensional separations that $p$-tyramine could be completely resolved more simply by 1-dimensional development using the second solvent, toluene-triethylamine 10:1. This also applied to 2-phenylethylamine. For tryptamine only the presence and relative visual intensity of its spot in the 2-dimensional chromatograms could be reported. Figure 2 shows 1-dimensional thin layer chromatography of the dansylated amines from diarrhoetic and healthy children and allows a quick visual comparison, particularly of $p$-tyramine. The calculated values for $p$-tyramine and phenylethylamine are set out in Table 3. These are expressed in terms of faecal solids which were obtained by drying $200 \mathrm{mg}$ specimens to constant weight over sulphuric acid. Three of the diarrhoetic infants $(D, G, M)$ 
Table 3 Comparison of the presence concentrations of faecal tyramine, phenylethylamine and tryptamine in diarrhoetic and healthy infants

\begin{tabular}{|c|c|c|}
\hline Amine & Diarrhoetic & Healthy \\
\hline \multicolumn{3}{|l|}{$p$-Tyramine } \\
\hline Present (scanned peak) & $13 / 13$ & $13 / 13$ \\
\hline $\begin{array}{l}\text { Concentration range } \\
(\mu \mathrm{M} / \mathrm{g} \text { faecal solids })\end{array}$ & $0 \cdot 3-27 \cdot 8$ & $0 \cdot 1-8 \cdot 8$ \\
\hline Mean value & $5 \cdot 6$ & $2 \cdot 0$ \\
\hline \multicolumn{3}{|l|}{ 2-Phenylethylamine } \\
\hline Present (scanned peak) & $10 / 13$ & $6 / 13$ \\
\hline $\begin{array}{l}\text { Concentration range } \\
\text { (nM/g faecal solids) }\end{array}$ & (10) $2 \cdot 0-9() \cdot 0$ & (6) $2 \cdot 1-9 \cdot 8$ \\
\hline \multicolumn{3}{|l|}{ Tryptamine ${ }^{*}$} \\
\hline Spot present in & $5 / 13$ & $4 / 13$ \\
\hline 2D TLC (Fig. 1) & $\begin{array}{l}1 \text { strong, } \\
2 \text { medium, } \\
2 \text { weak }\end{array}$ & 4 weak \\
\hline
\end{tabular}

${ }^{*}$ Estimate by visual appraisal only.

showed the presence of phenol which was confirmed by field desorption mass spectrometry. The results for tyramine were tested for significant difference between values obtained for the diarrhoetic and healthy groups. The results for faecal tyramine were tested by the Student $t$ test and a significant difference $(p=0.02)$ was found between the diarrhoetic and healthy groups. The data for tyramine was also organised into dietary groups. Applying the Welch $t$ test, for groups of uneven size, to this data, a highly significant difference $(p=0 \cdot 01)$ was found between tyramine concentrations of the groups on cow's milk diet and breast milk. The difference between tyramine concentrations of the cow's milk and cow's milk formulation groups was also highly significant $(p=0 \cdot 01)$. The difference between tyramine concentrations of the cow's milk formulation and breast milk groups showed that the significance $(p=0 \cdot 11)$ approached the ususal $10 \%$ level but the sample population was probably too small to permit a final assessment of significance.

\section{RECOVERIES AND REPRODUCIBILITY}

Recoveries of tyramine and phenylethylamine added to faeces and using the solvent extraction method were: $50 \mu \mathrm{mol}$ each amine, $81.9 \%$ (SEM $+2.3 \%, n=4)$ and $78.9 \% \quad($ SEM $+2.9 \%, n=4)$ respectively, and with $5 \mu \mathrm{mol}$ each amine, $76.0 \%$ $(\mathrm{SEM}+2 \cdot 8 \%, \mathrm{n}=4)$ and $74.1 \%(\mathrm{SEM}+2 \cdot 9 \%$, $n=4)$, respectively. The linearity of the solvent extraction method and densitometer readings was verified over the range $0 \cdot 25-50 \mu \mathrm{mol}$. The regression coefficients for tyramine and phenylethylamine were 0.9955 and 0.9978 respectively. The useful lower limit of detection was restricted by background to $0.2 \mathrm{nmol}$ for tyramine and phenylethylamine.

\section{Discussion}

The profiles of the primary amines in the 44 infants' stools, obtained as the field desorption spectra of their fluorescamine (lactone) derivatives were remarkably free from background, and were informative. A few specimens showed no, or only trace amounts of amines in relatively complex mixtures. Four showed the presence of cyclohexylamine, an amine foreign to the human body and a known carcinogen. It derives from the action of the gut microflora on cyclamates, ${ }^{5}$ which are used as sweeteners for children's medications. The profiles provided a most useful overview of primary amines in children's faeces. The data are summarised in Table 2.

While field desorption mass spectrometry is a powerful research tool which can readily provide the data such as in Table 2, its practice is not easy and the analysis of the fluorescamine (lactone) derivatives would be difficult to quantify. Consequently, in extending this study, we have based our efforts on the thin layer chromatography of the aminedansyl derivatives, thus using a simple established quantitative technique. ${ }^{3}$ We did use field desorption mass spectrometry, however, to establish by the dansylamine molecular ions the identity and position of amines on thin layer chromatography plates developed in one or two directions. Electron impact mass spectrometry had previously been used for the same purpose. ${ }^{6}$

The results show that the sick infants as a group had significantly higher concentrations of tyramine and phenylethylamine than those found in healthy infants (Table 3). Visual assessment of tryptamine levels indicated a similar situation. No correlation was found between type of gut infection and the presence of particular amines. The overall higher levels of the three amines from the diarrhoetic infants can readily be accounted for by any of one or more of several possibilities, including the following. Firstly, the short transit time associated with diarrhoea probably would not permit absorption of amines to be as great as in healthy infants. Secondly, a degree of malfunction of the digestive system would allow more protein tyrosine to reach the colonic microflora. Thirdly, the metabolic activity of the gut microflora may be higher than in healthy infants. Although these factors can explain quantitative differences between the sick and healthy infants the question remains - why did a few diarrhoetic infants and rather more healthy infants produce low 
Table 4 Type of milk diet related to faecal tyramine level

\begin{tabular}{lll}
\hline $\begin{array}{l}\text { Type milk } \\
\text { diet }\end{array}$ & $\begin{array}{l}\text { Infant } \\
\text { (Fig. 3) }\end{array}$ & $\begin{array}{l}\text { Tyramine } \\
\mu \text { mol/g dry wt }\end{array}$ \\
\hline $\begin{array}{l}\text { Cow's milk } \\
\begin{array}{l}\text { Breast fed } \\
\text { Cow's milk } \\
\text { formulation }\end{array}\end{array}$ & DGJSW & $12.72(3 \cdot 46), 6 \cdot 9-26 \cdot 0$ \\
$\begin{array}{l}\text { Soya milk } \\
\text { formulation } \\
\text { (humanised) }\end{array}$ & ACKOP & $0.68(0 \cdot 22)^{*}, 0 \cdot 2-1 \cdot 3$ \\
\hline
\end{tabular}

Values are given as means with standard error of means in parentheses followed by the range of values.

$*$ =significantly different from cow's milk diet, (Welch t-test, $p=0 \cdot 01$ ). Difference between the cow's milk formulation and breast fed groups approaches significance at the $10 \%$ level $(\mathrm{p}=0 \cdot 11)$.

amounts of amines? The answer appears to relate to the diets of the infants and specifically to the content of protein. Milk was the main item of diet for all infants. Information of the type of milk diet was obtained from records for 16 of the 26 infants. For those hospitalised with gastroenteritis this was the diet up to the time of admittance. The remaining 10 had no record or it was non-specific. In Table 4 the type of milk diet is related to faecal tyramine.

Cow's milk diet was associated highly significantly $(p=0.01)$ with the production of larger amounts of tyramine than was breast milk. Tyramine is produced by the action of decarboxylases on tyrosine. Although decarboxylases are present in human tissue, including the gut, studies support the contention that most tyramine arises by action of gut microbial decarboxylases. ${ }^{7}$ Tyrosine could reach the gut flora either on account of a much higher loading on the infant or because of the less digestible nature of bovine casein or both. The tyrosine content of cow's milk is more than four times the content of human milk, ${ }^{8}$ and even diluted there is the possibility of a substantial tyrosine overload. Given recent figures for the protein content of human milk as $0.8-0.9 \mathrm{~g} / 100 \mathrm{ml},{ }^{9}$ then formulations based on cow's milk and soya milk and with protein contents in the range $1.5-2.0 \mathrm{~g} / 100 \mathrm{ml}$ at the recommended dilution, may also produce a moderate tyrosine overload. The results show that tyramine concentrations associated with a cow's milk formulation diet are significantly lower than the tyramine levels obtained for unmodified cow's milk $(p=0 \cdot 01)$. Although the mean tyramine concentration for the cow's milk formulation group is higher than that for the breast fed group, the difference between the two groups only approaches significance at the $10 \%$ level $(p=0 \cdot 11)$. This result may reflect the small groups used for comparison, or differences due to different products. The lowest overload would be expected from the socalled 'humanised' milk formulations in which the casein/lactalbumin ratio of cow's milk has been adjusted to be close to that of human milk. (Table 4 , infant X). Only a trace of faecal tyramine was detected for the single infant on 'humanised' cow's milk formulation. It may be relevant to the occurrence of a tyrosine overload that cow's milk produces a tough casein curd which is difficult to digest and has been implicated in intestinal obstruction. ${ }^{10}$ Undigested curd may provide the substrate for tyramine production by the gut microflora. Of the 13 diarrhoetic infants, five were excreting $p$-tyramine in the range $2 \cdot 0-3.8 \mathrm{mg} / \mathrm{g}$ solids, the highest values being from infants aged 3-4 months. Not available for the subjects is any data on tyramine that may have been absorbed from the gut. Urine samples would have provided this information at least in part. Urines collected concurrently with the faeces were not available for this study because of the logistic problems.

This exploratory study shows that the infant diets with the highest tyrosine are associated with the highest levels of faecal $p$-tyramine. It should be stressed that if further studies confirm that some infant diets are related to high levels of faecal tyramine it is a condition that is both artificial and preventable. The effect of diet on tyramine production can readily be established by faecal amine analysis by thin layer chromatography as described.

This work was greatly assisted by funds provided by the Children's Medical Research Foundation, Sydney, Australia. We thank Ms Carolyn Booth for technical assistance and D J Best, Division of Statistics, CSIRO, for statistics consultation.

\section{References}

1 Slingsby JM, Boulton AA. Separation and quantitation of some urinary arylalkylamines. J Chromatogr 1976; 123: $51-6$.

2 Udenfriend $\mathrm{S}$, Stein $\mathrm{S}$, Bohlen $\mathrm{P}$, Dairman $\mathrm{W}$, Leimegruber W, Weigele $\mathrm{M}$. Fluorescamine: a reagent for assay of amino acids, peptides, proteins and primary amines in the picomole range. Science 1972; 178: $871-2$.

3 Seiler N, Weichmann M. TLC analysis of amines as their DANS-derivatives. Prog Thin Layer Chromatogr Related Methods 1970; 1: 95-144.

4 Murray KE, Ingles DL. Identification of amines and amino acids as their fluorescamine derivatives by field desorption mass spectrometry. Chem Ind 1979; 476-77.

5 Drasar BS, Renwick AG, Williams RT. The role of the gut flora in the metabolism of cyclamate. Biochem $J$ 1972; 129: 881-90. 
6 Creveling $\mathrm{Cr}$, Kondo K, Daly JW. Use of dansyl derivatives and mass spectrometry for identification of biogenic amines. Clin Chem 1968; 14: 302-9.

7 Melnykowyez J, Johansson KR. Formation of amines by intestinal microorganisms and the influence of chlortetracycline. J Exp Med 1955; 100: 507-17.

8 Paul AA, Southgate AT, Russell J. McCance and
Widdowson's: The composition of foods. First supplement. London: HM Stationary Office, 1980.

9 Picciano MF. The volume and composition of human milk. In: Infant and child feeding. The Nutrition Foundation. New York: Academic Press 1981; 49.

10 Cook R, Rickham P. Neonatal intestinal obstruction due to milk curds. J Pediatr Surg 1969; 4: 599-605. 